\title{
Catecholamine and cortisol levels in Oxford college rowers
}

\author{
R Pearson, G Ungpakorn and G A Harrison \\ Institute of Biological Anthropology, University of Oxford, Oxford, UK
}

\begin{abstract}
Urinary catecholamines and cortisol levels in two teams of Oxford college eights oarsmen were compared on three different day types: training days, racing days, and nonrowing days. Adrenaline and cortisol were raised on racing and training days compared to non-racing days. Noradrenaline was raised on training days, reflecting longer periods of physical exercise during training. There was evidence of a progressive lowering of adrenaline output over consecutive race days and that the outcome of the races had an effect on both adrenaline and cortisol. In addition to this there seemed to be differences in cortisol levels between the two teams of rowers on both racing days and nonrowing days.
\end{abstract}

(Br J Sports Med 1995; 29 : 174-177)

Keywords : adrenaline; cortisol; noradrenaline; rowing

It is well known that the physical strain of sports activity is associated with increases in catecholamines and cortisol in the body and that these hormone elevations are positively related to the intensity of exercise. ${ }^{1-4}$ However, in addition to physical strain, the mental stress of competition and the emotions associated with winning or losing have an effect on the secretion of hormones. Mason ${ }^{5} 6$ believed that psychological factors were a major determinant of hormone levels during exercise. Cambell et al reported that cortisol elevation in wrestlers was greater than that found in athletes using bicycle ergometers. Hill $e t$ al ${ }^{8}$ found that rowers engaged in time trials and racing had higher cortisol than when they engaged in vigorous practice exercise.

Unlike most investigations in published reports, this short study focuses on both the physical and psychological components of corporate sporting performance. It compares the effect of rowing competitions on two teams of eights oarsmen, where the performance of each team as a whole determines the differing outcomes of the races. It also examine the effect of repeated competitions over a short time span where the crew performance on one day directly affects the racing format and associated pressures for the following day.

\section{Methods}

Urine samples were collected from 16 young male rowers in Oxford. Their average age was 20.7 years

Address for correspondence: $R$ Pearson, Institute of Biological Anthropology, University of Oxford, 58 Banbury Road, Oxford OX2 6QS, UK (range 19.2-24.9 years). The rowers were the eight crew members of the first and second boats of an Oxford college. Samples from boat 1 were collected on three training days, four racing days, and two nonrowing days. Samples from boat 2 were collected on four racing days and two non-rowing days. The problems posed by field studies of volunteers meant that we were not able to collect samples on training days for boat 2 since, unlike the first boat, they trained at a different time of day to the races. In addition to this problem, no information was available about the activities of the rowers on non-rowing days.

One rower, from boat 1 , showed outstandingly high cortisol levels on the non-rowing days (mean value $2.56 \mu \mathrm{g} \cdot \mathrm{h}^{-1}$ compared to the mean for the other rowers of $0.53 \mu \mathrm{g} \cdot \mathrm{h}^{-1}$ ). All his results for non-rowing days were excluded from the analysis.

Total urine samples were collected over a $3.5 \mathrm{~h}$ period, $13.30-17.00$ hours for boat 1 , and $12.00-15.30$ for boat 2 , which in each case included the actual race for both boats and the training period for boat 1 . Training periods were about $1.5 \mathrm{~h}$ in length, whereas the race itself could take no more than 5-6 min. The four race days were the four consecutive Torpids Regatta days and each boat raced at precisely the same time each day. Boat 1 raced $1.5 \mathrm{~h}$ after boat 2 . To win a particular race a boat has to catch up with and 'bump' the boat in front. If this happens the 'bumped' crew do not finish the rest of the course. The outcome of each race was recorded.

After the total volume of urine was recorded, smaller samples were frozen at $-30^{\circ} \mathrm{C}$ on the same day. Samples for catecholamine analysis contained approximately $0.25 \%$ sodium metabisulphite as preservative. Samples for cortisol analysis did not contain any preservation. Sodium metabisulphite interferes with cortisol analysis. The samples were analysed for noradrenaline, adrenaline, and cortisol at random on a later date, using high performance liquid chromatography as previously described. ${ }^{9-10}$

Hormone flow values were transformed to a $\log _{10}$ scale to achieve normal distribution for statistical analyses. Analysis of variance and $t$ tests were carried out to determine any significant differences in hormone levels due to day type and team. In addition, the relationship between hormone excretion rates and urine flow was examined. Urine flow rates were only significantly associated with cortisol excretion in boat 1 and correcting for urine flow did not affect any 
conclusions from other statistical tests. For this reason the analyses reported here are based on uncorrected values.

\section{Results}

Mean untransformed rates of hormone excretion on each day type (training, race, and non-rowing) for each boat are shown in Table 1 .

An analysis of variance on log transformed values to test the effect of day type (training, race and nonrowing) on the variation of mean hormone levels for individual rowers from boat $I$ was carried out. The results showed that there was significant heterogeneity for all three hormones on the various days (noradrenaline $\mathrm{F}=12.32, \quad P<0.001$; adrenaline $\mathrm{F}=$ 15.80, $P<0.001$; and cortisol $\mathrm{F}=8.69, P=0.002$ ). A similar analysis of variance for boat 2 could not be conducted since boat 2 had hormone values for only two day types (race and non-rowing).

Several $t$ tests were carried out on mean hormone values for crew members in both boats. Comparison of race and non-rowing days showed that adrenaline was higher on race days in both boats 1 and $2(t=3.59$, $P=0.005$, and $t=5.23, P<0.001$, respectively). Mean cortisol output was also higher on race days $\left(t_{1}=2.92, P=0.013\right.$, and $\left.t_{2}=3.51, P=0.004\right)$. Although noradrenaline output was higher on race days for both boats, the differences were not statistically significant.

A $t$ test comparing mean hormone levels from boat 1 on training days with race and non-rowing days showed that training and race days only differed significantly for noradrenaline output. Noradrenaline was higher on training days $\left(t_{1}=2.97, P=0.012\right)$. In the comparison between training and non-rowing days, output of all three hormones was higher on training days (noradrenaline $t_{1}=5.30, P<0.001$; adrenaline $t_{1}=6.63$, $P<0.001$; and cortisol $\left.t_{1}=3.58, P=0.004\right)$.

A $t$ test comparing hormone output between the two boats showed that boat 2 had significantly higher cortisol than boat 1 on race days $(t=3.86, P<0.001)$ and non-rowing days $(t=3.08, P=0.005)$. There were no significant differences between boats for noradrenaline and adrenaline on these two day types.

Since race days were consecutive, an analysis of variance and a Duncan's multiple range test ${ }^{11}$ to
Table 2. Summary of an analysis of variance and a Duncan's multiple range test to investigate the effect of race day number on log transformed hormone outputs in the two crews of eight oarsmen from boats 1 and 2 . There were four consecutive race days.

\begin{tabular}{lccl}
\hline & $F$ & $\mathrm{P}$ & Nature of change \\
\hline $\begin{array}{l}\text { Boat 1 } \\
\text { Noradrenaline }\end{array}$ & 1.52 & $\mathrm{~ns}$ & \\
$\quad$ Adrenaline & 3.17 & 0.048 & decline day 1 to 4 \\
$\quad$ Cortisol & 2.50 & $\mathrm{~ns}$ & \\
$\begin{array}{l}\text { Boat 2 } \\
\quad \text { Noradrenaline }\end{array}$ & 2.71 & $\mathrm{~ns}$ & \\
$\quad$ Adrenaline & 3.96 & 0.022 & decline day 1 to 3 \\
$\quad$ Cortisol & 3.44 & 0.009 & raised on day 4 \\
\hline
\end{tabular}

Degrees of freedom $=3$

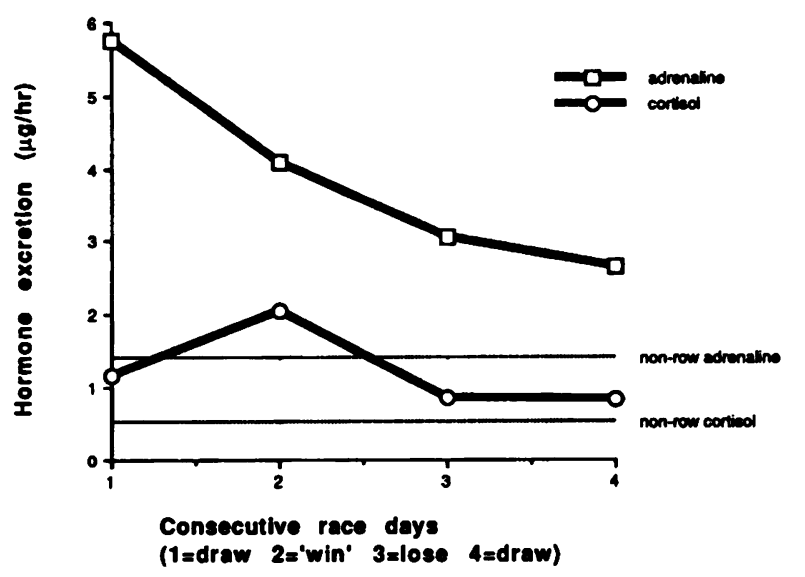

Figure 1. Boat 1. Hormone changes over four race days compared to mean non-rowing day values.

investigate the effect of race day number on hormone output was undertaken (Table 2). Boat 1 gained no victories other than a technical win due to their opponents' equipment failure. Boat 1 adrenaline showed a significant decline from day 1 to day $4(\mathrm{~F}=3.17, P=$ 0.048 ). No such effect was found with noradrenaline or cortisol. In the case of cortisol, a rise in hormone levels took place on the second day of the race, which corresponded to the technical win.

Boat 2 won all four races and a significant decline in adrenaline was also observed between days 1 and 3, but

Table 1. Mean hormone excretion rates $\left(\mu \mathrm{g} \cdot \mathrm{h}^{-1}\right)$ in two crews of eight oarsmen from two boats on three day types (training, racing, and non-rowing)

\begin{tabular}{lcrr}
\hline & Training & Racing & Non-rowing \\
\hline Boat 1 & & & \\
Noradrenaline & $43.08(11.14)$ & $25.22(15.3)$ & $16.34(7.63)$ \\
Adrenaline & $4.65(1.59)$ & $3.82(3.20)$ & $1.61(0.88)$ \\
Cortisol & $1.16(0.75)$ & $1.21(0.94)$ & $0.79(0.83)$ \\
Boat 2 & na & $21.33(8.91)$ & $1.91(7.06)$ \\
Noradrenaline & na & $4.73(2.48)$ & $18.94(9.62)$ \\
Adrenaline & na & $2.19(1.34)$ & $0.53(0.30)$ \\
Cortisol & & & $0.99(0.55)$ \\
\hline
\end{tabular}

All values are mean (s.d.); na = not available

$n=8$, except ${ }^{*}$ where one rower excluded 


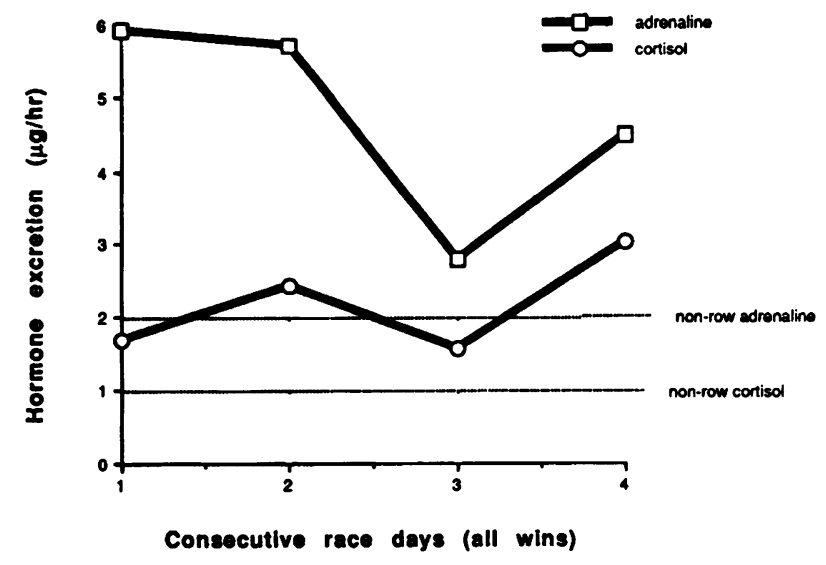

Figure 2. Boat 2. Hormone changes over four race days compared to mean non-rowing day values.

on the last race day adrenaline was raised $(\mathrm{F}=3.96$, $P=0.022$ ). Boat 2 cortisol on the last race day also showed a significant elevation compared to the previous days $(\mathrm{F}=3.44, P=0.036)$. No effect was found with noradrenaline. The adrenaline and cortisol findings are represented graphically in Figures 1 and 2.

\section{Discussion}

Although this analysis is based upon observations on a rather limited number of subjects under field conditions, it has produced some quite clear findings. Subject number can be quite small when conditions are extreme, activities are fairly standardized, and individuals can be used as their own 'controls'. The main findings essentially confirm previously published data $^{1-4}$ in that they show that competitive sport is associated with raised output of adrenaline, noradrenaline, and cortisol.

The study further indicates that hard training produces the same order of hormone response as racing itself. Indeed, noradrenaline levels, which closely follow physical exercise, tend to be even higher as a result of training, no doubt because much more physical work is being done during training than in the comparatively short time of a race. Petraglia et al ${ }^{4}$ showed that runners engaged in long distance races produced more cortisol than runners in short races. The data presented in this paper show that training generates more or less the same 'stresses' as racing. Such 'stresses' would include both a physical and a mental element for adrenaline and cortisol. This result differs from that reported by Hill et $a l^{8}$ who found that rowing 'time trials' and races resulted in higher cortisol than practice rowing sessions.

The analysis also shows a reduction in adrenaline response over the four consecutive days of racing. This is very clear in the mean values for boat 1 , although it is not shown by every individual, and only occurs over the first three days in boat 2 . The latter phenomenon may have been related to the special pressures of the last day's racing. After three successive wins the crew in this boat only needed one more to win their 'blades' - the greatest accolade. The crew of the first boat did not experience those special pressures although it may perhaps be of some significance that the high cortisol of their second day of racing corresponded with the mental disturbance of a 'technical win'. This occurred through an oarsman in the boat ahead breaking an oar, an event which caused one rower in the winning boat to report: 'Nabbed Lincoln's boat in 20 strokes. Their number 7 snapped his blade in two. We sat at the side of the river, as other crews passed by, a mixture of pleasure for some, total dissatisfaction for others.' Other authors have reported that the outcome of competitive matches can affect hormone levels. Booth et $a l^{12}$ and Mazur et $a l^{13}$ found that testosterone was raised in winners of tennis matches, although no effect on cortisol was discovered.

Another phenomenon which may be worth following up is the difference in cortisol levels between the two boats on non-rowing days as well as rowing ones. This corresponds with very clear differences in the performance of the boats and may well reflect long standing corporate attitudes and expectations. However, it should be noted that the timings of urine collection were not quite the same, especially for race days when boat 2 raced earlier in the afternoon than boat 1 . It is, therefore, possible that one is dealing with circadian rhythm effects which are known to occur in both catecholamines and corticosteroids, ${ }^{14-16}$ although these are not evident in the adrenaline results.

Does a study such as this provide any insight into the roles of the hormones themselves? It was certainly expected that racing would be associated with raised adrenaline - the quintessential 'flight fight hormone'. There is abundant evidence that adrenaline output is stimulated by increasing mental arousal ${ }^{17}{ }^{18}$ and helps to provide the additional energy requirements often associated with such arousal. Clearly there is peak apprehension and excitement in preparing for racing! The 'acclimatization' in adrenaline output implies that that apprehension becomes less with experience, possibly to the disadvantage of performance.

The role of cortisol is more ambiguous. It is frequently seen as reflecting levels of affect, ${ }^{19}$ but the empirical evidence for this is poor. It has often been seen as enhancing defence mechanisms to stress although Munck $e t a l^{20}$ point out that it is more likely to act as a suppressor of this mechanism. It is suggested by Pollard et $a l^{21}$ that it may reflect levels of general emotional state- good and bad-and the findings of the study would be compatible with such a view.

\section{Acknowledgements}

We are grateful for the co-operation of the two crews from St John's College, Oxford, who participated in the study.

\section{References}

1 Lavoie JM, Bonneau MC, Roy JY, Brisson GR, Hélie R. Effect of dietary manipulations on blood glucose and hormonal responses following supramaximal exercise. Eur J Appl Physiol 1987; 56: 109-14.

2 Riad-Fahmy D, Cook NJ, Read GF, Walker RF, Harris B. Changes in adrenal and testicular activities monitored by salivary sampling in males throughout marathon runs. Eur J Appl Physiol 1986; 55: $634-38$. 
3 Sutton JR, Coleman MJ, Casey J, Lazarus L. Androgen responses during physical exercise. BMJ 1973; $1: 520$.

4 Petraglia F, Barletta C, Facchinetti F, Spinazzola F, Monzani A Scavo $D$, et al. Response of circulating adrenocorticotropin, betaendorphin, beta-lipotropin and cortisol to athletic competition. Acta Endocrinol (Copenh) 1988; 118 : 332-36.

5 Mason JW. Emotion as reflected in patterns of endocrine integration. In: Levi L, ed. Emotions. Their parameters and measurement. New York: Raven Press, 1975 : 143-82.

6 Mason JW. A review of psychoendocrine research on the sympathetic-adrenal medullary system. Psychosom Med 1968; 30 631-53.

7 Campbell BC, O'Rourke MT, Rabow MW. Pulsatile response of salivary testosterone and cortisol to aggressive competiton in young males. Am J Phys Anthropol 1988; 75 : 193-94.

8 Hill SR, Goetz FC, Fox HM, Murawski BJ, Krakauer LJ, Reisenstein RW, et al. Studies on adrenocortical and psychological response to stress in man. Arch Intern Med 1956; 97: 269-98.

9 Jenner DA, Brown MJ, Lhoste FJM. Determination of $\alpha$ methyldopa, $\alpha$-methylnoradrenaline, noradrenaline, and adrenaline in plasma using HPLC with electrochemical detection. $J$ Chromatgr 1981; 224: 507.

10 Jenner DA, Richards J. Determination of cortisol and cortisone in urine using HPLC with UV detection. J Pharmacol Biomed Annals $1985 ; 3$ : 251.

11 Miller RG. Simultaneous statistical inference. New York: SpringerVerlag, 1981.

12 Booth A, Shelley G, Mazur A, Tharp G, Kittoks, R. Testosterone and winning and losing in human competition. Hormones Behav 1989; 23 : 556-71.

13 Mazur A, Lamb TA. Testosterone, status and mood in human males. Hormones Behav 1980; 14: 236-46.

14 Patkai $P$. The diurnal rhythm of adrenaline secretion in subjects with differing working habits. Acta Physiol Scand 1971; 81: 35-46.

15 Prinz PN, Halter J, Benedetti C, Raskind M. Circadian variation of plasma catecholamines in young and old men: relation to rapid eye movement and slow wave sleep. J Clin Endocrinol Metab 1979: 49: 300-4.

16 Jenner DA. Population studies of variation in catecholamine and corticosteroid excretion. (D Phil Thesis). Institute of Biological Anthropology, University of Oxford, 1985

17 Frankenhaeuser $M$. The role of the peripheral catecholamines in adaptation to understimulation and overstimulation. In: Serban, G, ed. Psychopathology of human adaptation. New York: Plenum: 173-91.

18 Jenner DA, Harrison GA, Prior IAM. Catecholamine excretion in Tokelauans living in three different environments. Hum Biol 1987, 59: 165-72.

19 Frankenhaeuser M. A biopsychosocial approach to work life issues. Int J Health Sero 1989; 19: 747-58.

20 Munck A, Guyre PM, Holbrook NJ. Physiological functions of glucocorticoids in stress and their relationship to pharmacological actions. Endocrinol Rev 1984; 5 ; 25-44.

21 Pollard TM, Harrison GA, Ungpakorn G. Adrenaline and cortisol responses to job experience. Ann Hum Biol 1994; 21 : 98. 